Synthesis, part of a Special Feature on Practicing Panarchy: Assessing Legal Flexibility, Ecological Resilience, and Adaptive Governance in U.S. Regional Water Systems Experiencing Climate Change

\title{
Cross-interdisciplinary insights into adaptive governance and resilience
}

\author{
Craig Anthony (Tony) Arnold ${ }^{1}$, Hannah Gosnell ${ }^{2}$, Melinda H. Benson $^{3}$ and Robin K. Craig ${ }^{4}$
}

\begin{abstract}
The Adaptive Water Governance project is an interdisciplinary collaborative synthesis project aimed at identifying the features of adaptive governance in complex social-ecological institutional systems to manage for water-basin resilience. We conducted a systematic qualitative meta-analysis of the project's first set of published interdisciplinary studies, six North American basin resilience assessments. We sought to develop new knowledge that transcends each study, concerning two categories of variables: (1) the drivers of change in complex water-basin systems that affect systemic resilience; and (2) the features of adaptive governance. We have identified the pervasive themes, concepts, and variables of the systemic-change drivers and adaptive-governance features from these six interdisciplinary texts using qualitative methods of inductive textual analysis and synthesis. We produced synthesis frameworks for understanding the patterns that emerged from the basin assessment texts, as well as comprehensive lists of the variables that these studies uniformly or nearly uniformly addressed. These study results are cross-interdisciplinary in the sense that they identify patterns and knowledge that transcend several diverse interdisciplinary studies. These relevant and potentially generalizable insights form a foundation for future research on the dynamics of complex social-ecological institutional systems and how they could be governed adaptively.
\end{abstract}

Key Words: adaptive governance; interdisciplinary; qualitative textual analysis; resilience; systemic-change drivers

\section{INTRODUCTION}

The Adaptive Water Governance (AWG) project is an interdisciplinary collaborative synthesis project aimed at identifying features of adaptive governance in complex socialecological-institutional systems, particularly governance features for managing for water-basin resilience under stresses caused by climate change (Cosens et al. 2014a, Gunderson et al. 2017). The AWG project, led by coprincipal investigators Barbara Cosens and Lance Gunderson, brought together over two dozen researchers in many different disciplines across the natural and ecological sciences, social and policy sciences, law, engineering, and humanities from 2013 to 2016.

The AWG project linked the concepts and science of socialecological resilience with the theory and practice of governance, including law and policy (Cosens et al. 2014a). The project participants adopted the Walker and Salt (2012) definition of social-ecological resilience: "a measure of the amount of perturbation a social-ecological system can withstand while maintaining its structure and functions; it describes the ability of a complex system to continue to provide the full range of ecosystem services in the face of change" (Cosens et al. 2014a:7). The project defined governance as "the means through which political actors choose goals and make decisions and the means through which they take action to achieve those goals" (Cosens et al. 2014a:9). Adaptive governance is governance that enables society to adapt to disturbances and changes by navigating the dynamic, multiscalar nature of social-ecological-institutional systems (Cosens et al. 2014a).

The AWG project provided an ideal opportunity to conduct a systematic qualitative meta-analysis of the project's first set of published interdisciplinary studies to identify knowledge about adaptive governance and resilience that transcends each study. If clear, pervasive patterns could be identified from studies of several different basins conducted by different interdisciplinary teams using different interdisciplinary methodologies, these patterns would likely form significant generalizable insights that could improve understanding of adaptive water governance in complex social-ecological-institutional systems. We use the term "socialecological-institutional systems," because: (1) the AWG project gives particular attention to the roles of legal and governance institutions in systemic change and resilience (Cosens et al. 2014a); and (2) institutions, the rules that shape human behavior, are systems that are analytically distinct from social systems such as economies, politics, and local culture (Arnold et al. 2014, Sjöstedt 2015). Institutions shape and are shaped by both social systems and ecosystems.

We have systematically assessed the knowledge that the AWG project has generated concerning: (1) the drivers of change in complex social-ecological-institutional water systems that affect their resilience; and (2) features of adaptive governance in water basins. We have defined drivers of change to include both exogenous drivers and endogenous change-producing variables as differentiated by Walker et al. (2012). We have analyzed the published texts of resilience assessments of six North American water basins prepared by AWG teams, which are texts of interdisciplinary insights from in-depth case studies.

By analyzing and synthesizing the major themes, concepts, and variables from these six texts, using a qualitative, inductive textual analysis, we have identified the drivers of systemic change in water basins and the features of adaptive water governance that appeared in at least five of the six AWG basin assessments. The six diverse basin assessments had large numbers of relevant systemic-change drivers and adaptive-governance features in common, similar in scope to the exhaustive lists developed by Ostrom in her studies of complex social-environmental systems and institutional emergence (Ostrom 2009, McGinnis 2011). We have organized and listed these variables in Appendices 1 and 2. We have also synthesized them into two frameworks based on

\footnotetext{
${ }^{1}$ Brandeis School of Law, Department of Urban and Public Affairs. Center for Land Use and Environmental Responsibility, University of Louisville, Louisville, ${ }^{2}$ College of Earth, Ocean, and Atmospheric Sciences, Oregon State University, Corvallis, ${ }^{3}$ Haub School of Environment and Natural Resources, University of Wyoming, Laramie, ${ }^{4}$ S.J. Quinney College of Law, University of Utah, Salt Lake City
} 
cross-assessment patterns and themes. In the framework for systemic-change drivers, human communities' alteration of key ecological processes and features is the central category of change driver, but change is also driven by ecosystem conditions and processes, social-political-economic forces, evolving institutions, and ecosystem feedbacks to human communities, and the effects of these systems or categories on one another. The framework for adaptive governance contains a variety of features organized around four elements of governance: goals, structure, methods, and resources.

These insights are "cross-interdisciplinary" in the sense that they are syntheses of the results of six different interdisciplinary studies undertaken by diverse teams of scholars. Thus, our results transcend not only individual disciplines but also any single interdisciplinary approach. Our analytical frameworks and lists may be useful to other interdisciplinary research teams in other water basins or social-ecological-institutional systems and should be tested and refined for generalizable application.

\section{FOUNDATIONS}

Collaborations across research disciplines are necessary to understand and address complex problems that have cross-scale, dynamic interactions among many environmental systems (e.g., watersheds, wetlands, climate), social systems (e.g., economies, politics, communities), and governance institutions (e.g., legal regimes, formal authorities, informal governance; Heemskerk et al. 2003, Arnold 2004, Gray 2008). No single discipline or even grouping of a few related disciplines possesses the theoretical frameworks and research methodologies required to fully comprehend the complexities of diverse interlinked systems.

Results from attempts at interdisciplinary collaboration have been mixed at best. The barriers to collaborating across disciplines are well known: lack of incentives to do so, bureaucratic barriers in organizations defined by disciplines, the usual challenges of teamwork, and the habits and patterns of rigidly thinking within one's own disciplinary paradigms (e.g., Gray 2008). Moreover, many different types of research fall into the broad category of interdisciplinary research, ranging from conceptual frameworks built on insights from only two disciplines to entirely new disciplines created from transdisciplinary collaboration (Fairclough 2005, Stokols et al. 2005, Dewulf et al. 2007).

Some of the most important interdisciplinary work on understanding complex systems has been in the areas of adaptive governance (Chaffin et al. 2014a) and the dynamics of socialecological-institutional systems (Gunderson and Holling 2002). However, many studies have integrated insights from only two or three disciplines, such as law and ecology (e.g., Garmestani and Allen 2014) or ecology, economics, and sociology (Scheffer et al. 2002). Moreover, many interdisciplinary studies of adaptive governance or systemic dynamics are either primarily theoretical (Chaffin et al. 2014a) or based on empirical evidence from one particular system, such as the Florida Everglades (Light et al. 2005) or Swedish wetlands (Olsson et al. 2004). The benefits of interdisciplinary studies of complex social-ecological-institutional systems can be expanded through the systematic qualitative metaanalysis and synthesis of multiple interdisciplinary case studies (Noblit and Hare 1988, Grubert and Siders 2016). Through inductive identification of patterns of system-change drivers and adaptive-governance features that transcend specific case studies and their methodologies, interdisciplinary theories or frameworks of these phenomena can be developed and evaluated.

\section{THE ADAPTIVE WATER GOVERNANCE PROJECT}

Several aspects of the AWG project make it well suited to a qualitative meta-analysis study. First, the AWG project produced resilience assessments for each of six North American water basins and published them in a special symposium issue of the Idaho Law Review in late 2014 (Vol. 51, No. 1): Anacostia (DC, MD; Arnold et al. 2014); Columbia (ID, WA, OR, BC, MT, WY, CA, NV, UT; Cosens and Fremier 2014); Everglades (FL; Gunderson et al. 2014); Klamath (OR, CA; Chaffin et al. 2014b); Middle Rio Grande (NM; Benson et al. 2014); and Platte (NE, CO, WY; Birge et al. 2014).

Each assessment was produced by a different interdisciplinary team of researchers (Appendix 1). These published assessments are texts that were analyzed for cross-basin, cross-study patterns. Given that these published assessments are the focal point of our study, we will refer only to the basin assessments by basin name, not author and publication years, unless referring to specific material from particular pages in the publications.

Second, both the basins' characteristics and the methods used by the six teams of researchers to assess the basins were diverse. Thus, any clear patterns discerned from these assessments form general knowledge about adaptive governance and resilience that is not limited to a particular type of basin or a particular type of analytical methodology. Table 1 represents several of the dimensions across which the basins differ from one another (see also Tables 2-8 in Gunderson et al. 2017 for basing-by-basin details). Table 2 summarizes the teams' various analytical tools and methods of classifying systemic change by basin assessment.

Table 1. Range of basin characteristics.

\begin{tabular}{|c|c|}
\hline $\begin{array}{l}\text { Basin } \\
\text { Characteristic }\end{array}$ & Range \\
\hline $\begin{array}{l}\text { Region in the } \\
\text { United States }\end{array}$ & $\begin{array}{l}\text { Mid-Atlantic; Southeast; Great Plains; Southwest; } \\
\text { Pacific Northwest }\end{array}$ \\
\hline Basin size & $\begin{array}{l}\text { From } 173 \text { square miles in the Anacostia to } 258,000 \\
\text { square miles in the Columbia }\end{array}$ \\
\hline Climate & Humid; arid; mixed \\
\hline $\begin{array}{l}\text { Settlement } \\
\text { patterns }\end{array}$ & Urban; rural; mixed \\
\hline $\begin{array}{l}\text { Dominant } \\
\text { hydrology }\end{array}$ & $\begin{array}{l}\text { E.g., surficial water flows through wetlands in the } \\
\text { Everglades; modified riverine pulse floods in the Platte; } \\
\text { long and high-volume, but dammed, river-channel flow } \\
\text { in the Columbia }\end{array}$ \\
\hline Landscapes & $\begin{array}{l}\text { Various mixes of forests, plains, mountains, wetlands, } \\
\text { urbanized areas, farmland, and deserts }\end{array}$ \\
\hline $\begin{array}{l}\text { Number of } \\
\text { relevant } \\
\text { jurisdictions }\end{array}$ & $\begin{array}{l}\text { From } 2 \text { nations, } 8 \text { states, } 1 \text { province, and } 15 \text { Indian tribes } \\
\text { in the Columbia to just } 1 \text { state but many different federal, } \\
\text { state, and local agencies and } 2 \text { Indian tribes in the } \\
\text { Everglades }\end{array}$ \\
\hline $\begin{array}{l}\text { Influence of } \\
\text { federal laws }\end{array}$ & $\begin{array}{l}\text { More influence of the Endangered Species Act in the } \\
\text { American West; more influence of the Clean Water Act } \\
\text { in the American East }\end{array}$ \\
\hline
\end{tabular}


Table 2. Comparisons of basin methodologies.

\begin{tabular}{|c|c|c|}
\hline & Primary Analytical Tools & Systemic Change Classifications \\
\hline Anacostia & $\begin{array}{l}\text { Historical-institutional analysis. } \\
\text { Institutional-Social-Ecological Dynamics (ISED) framework examining } \\
\text { dynamics within and across ecological, social, and institutional systems. }\end{array}$ & $\begin{array}{l}\text { Five institutional-social-ecological regimes since } \\
\text { pre-European settlement. }\end{array}$ \\
\hline Columbia & $\begin{array}{l}\text { Walker and Salt list of resilience features. } \\
\text { Surveys and interviews of experts re: systemic resilience. } \\
\text { Ecosystem services heuristics. }\end{array}$ & $\begin{array}{l}\text { Four major historical eras since pre-European } \\
\text { settlement as four phases in adaptive cycle (with } \\
\text { impending possible regime shift). }\end{array}$ \\
\hline Everglades & $\begin{array}{l}\text { Historical-institutional analysis. } \\
\text { Focus on legal regimes and adaptive management. }\end{array}$ & 15 governance-management regimes since 1900. \\
\hline Klamath & $\begin{array}{l}\text { Adaptive cycle heuristic. } \\
\text { Social-science field research. } \\
\text { Historical social-ecological analysis. }\end{array}$ & $\begin{array}{l}\text { Four major historical eras since pre-European } \\
\text { settlement as four phases in adaptive cycle (with } \\
\text { impending possible regime shift). }\end{array}$ \\
\hline Middle Rio Grande & $\begin{array}{l}\text { Resilience theory analytics (focus on change across thresholds and on } \\
\text { identified tipping points, but without full use of adaptive cycle or } \\
\text { panarchy frameworks). } \\
\text { Relationships among governance-system, social-system, and } \\
\text { hydrological-system structures. }\end{array}$ & $\begin{array}{l}\text { Major contrasts between presettlement and current } \\
\text { ecosystem functions, structures, and services. }\end{array}$ \\
\hline Platte & $\begin{array}{l}\text { Ecosystem services heuristics. } \\
\text { Panarchy theory heuristics. } \\
\text { Focus on institutional effects on ecosystem services. }\end{array}$ & $\begin{array}{l}\text { Major contrasts between presettlement and current } \\
\text { ecosystem functions, structures, and services. }\end{array}$ \\
\hline
\end{tabular}

Despite a common research inquiry into the factors affecting the resilience and adaptive governance of each respective basin, each team developed its own methodology. Initial plans by the teams to use the Resilience Alliance's workbooks for conducting resilience assessments (Resilience Alliance 2007, 2010) were quickly abandoned because of the workbooks' inadequacies. There was no attempt to quantify or statistically test the relevance of variables influencing systemic change or adaptive governance. There was no common model that was applied and tested in each basin. The various qualitative, narrative approaches undertaken by the assessment teams reflected a belief that no single methodology is adequate to characterize resilience in every complex social-ecological-institutional system. Thus, when the basin assessments reveal shared insights, those revelations are more likely to point to significant and generalizable observations about AWG, rather than to reflect biases of a shared analytical method.

All teams employed some degree of narrative historical analysis, describing ecosystem, social system, and institutional conditions and changes in the basin over time. However, these common features did not form a standard cross-basin methodology (see Table 2). The teams varied in the heuristics they used, ranging from more emphasis on cross-system institutional dynamics (Anacostia, Everglades), social and institutional effects on ecosystem services (Columbia, Platte), and adaptive-cycle dynamics within social-ecological governance systems (Klamath, Middle Rio Grande). In addition, the Columbia and Klamath teams used social-science research methods to gather empirical field data, and the Anacostia team developed a new analytical framework, the Institutional-Social-Ecological Dynamics (ISED) Framework, to describe the evolving dynamics within and across categories of ecological, social, and institutional systems (Arnold et al. 2014). Likewise, the texts of the six basin assessments contained different ways of classifying systemic changes in the basins, ranging from major regime shifts (Anacostia, Everglades), movement through the phases of the adaptive cycle (Columbia, Klamath), and substantial changes in ecosystem structure and function from the presettlement era to the present (Middle Rio Grande, Platte; Table 2).

Third, the AWG project was interdisciplinary at three different levels. At the project group level, especially among the core group members (identified in Appendix 1), the project was intentionally aimed at interdisciplinary collaboration and synthesis. For example, at a planning workshop, the core team members engaged in a guided group discussion to frame the project's research questions and identify the project's synthesis goals. This facilitated dialogue for cross-disciplinary communication, based on the Toolbox Project (O'Rourke and Crowley 2013), explored the language, concepts, research methodologies, and even visual images that each participant brought from his or her disciplines to the group's inquiries. Comparisons, contrasts, and syntheses of the participants' contributions were made. The participants decided to address their common research questions by assessing the resilience of the project's six basins, yet with six distinct assessment teams developing their own methodologies for assessment. 
At the basin-assessment team level, each team was composed of several researchers representing a diverse array of disciplines (Appendix 1). For example, researchers studying the Anacostia River basin brought expertise and insights from law, planning, public policy, political science, geography, geology, hydrology, sociology, anthropology, history, economics, and psychology to their work. The Platte River basin team had a different mix that includes some of the same social and policy sciences as the Anacostia team, but with more representation from natural resources management and environmental sciences, including ecology, biology, and soil biochemistry. Each team collaborated to develop a resilience assessment of its respective basin that drew upon its members' diverse disciplinary backgrounds. Our review of the six resilience assessments shows that each assessment synthesizes data and concepts from many different disciplines, weaving these diverse insights into a single analytical text.

At the individual team-member level, each team was composed of scholars each of whom engages in interdisciplinary research. The 25 coauthors of the basin resilience assessments have training or experience in 29 different disciplines (Appendix 1). All of the basin resilience assessment authors, except one, have training or experience in more than one discipline. The disciplines are distributed across several broad, diverse categories, including the humanities, the social sciences, the natural sciences, policy systems design and management, and physical systems design and management. The disciplines that are most represented are law $(n=12)$, public policy $(n=7)$, geography $(n=6)$, natural resource management $(n=6)$, environmental science $(n=5)$, and ecology $(\mathrm{n}=5)$.

The broad interdisciplinary perspectives of the AWG project researchers helped to make the basin resilience assessments themselves interdisciplinary in nature. The basin assessment scholars regularly use their backgrounds in multiple disciplines to engage in interdisciplinary research, as their previous work shows (e.g., Arnold 2004, DeCaro and Stokes 2013, Cosens et al. 2014b, Chaffin et al. 2014a, Garmestani and Allen 2014). Moreover, research shows that systematic and sustained experience in a discipline, whether through formal training or repeated research, influences how a scholar will perceive and frame a phenomenon and then go about researching it (Fry 2001, Fairclough 2005, O'Rourke and Crowley 2013). According to epistemic network theory, humans form new, networked frameworks of knowledge, thinking, and analysis from mental connections that they make among the ideas and methods that they use from multiple disciplines, both individually and through group work (Heemskerk et al. 2003, Shaffer et al. 2009). Interdisciplinary research collaborations with others affect a scholar's capacity to see a phenomenon from multiple perspectives and to synthesize these perspectives (Fry 2001, Heemskerk et al. 2003, Stokols et al. 2005). In the AWG project, interdisciplinary connections were made at three levels: (1) within the individual scholar's mind; (2) among the basin resilience assessment team; and (3) through syntheses of the collective body of scholarship for the AWG project.

\section{METHODS}

We studied the six basin resilience assessments for their identification of drivers of systemic change and features of adaptive governance by coding the text of each assessment for themes, concepts, and variables, and then synthesizing the patterns that emerged from the textual analysis. We coded Microsoft Word files of the published assessments' texts in NVivo, a qualitative-data analysis software program developed by QSR International and commonly used in social-science research (Bringer et al. 2004, Bazeley and Jackson 2013). Qualitative analysis of the six basin resilience assessment for common themes and patterns is an appropriate method for developing crossdisciplinary theory because the assessments are both texts containing verbal data about common research questions on basin resilience and adaptive water governance (Strauss 1987, Fairclough 2005, Thomas and Harden 2008, Bazeley and Jackson 2013) and rich empirical case studies using diverse data of basin conditions, historical narratives of systemic changes, and critical analyses of basin resilience and governance (Eisenhardt and Graebner 2007).

Instead of looking for specific features of a preconceived theory or model in the texts, we used multiple iterations of analysis and synthesis to construct theoretical frameworks from the language and ideas of the textual sources themselves and from deep, critical reflection on the themes, concepts, and variables communicated by each basin team (Strauss 1987, Corbin and Strauss 1990). The texts and coded nodes in this project went through seven iterations of analysis and synthesis.

A single analyst, Tony Arnold, coded all the texts because unavoidable time, financial, and personnel constraints. It would have been preferable to have at least one other researcher code and to assess the coding with a reliability test of the overlap between two coders' results (higher overlap = higher reliability), although Bazeley and Jackson (2013) question the need for multiple coders and coding consistency because coding is a tool for thinking and analysis and not meant to be replicable data.

Arnold used five important checks on coder bias: (1) an intentionally iterative inductive coding process; (2) a process of disciplined and critical self-reflectivity to identify and control personal and disciplinary biases (Bettez 2015), including recoding, annotation, and journaling processes; (3) intentional avoidance of predictive models, theories, or synthesis works (e.g., Cosens et al. 2014a) when coding; (4) careful analysis of each assessment text in the second and third iterations of coding for each concept and variable coded in any of the assessment texts in the first iteration, thus allowing insights from later-coded texts to inform the coding of earlier-coded texts; and (5) review and feedback from at least one coauthor of each basin assessment. Some of the results of the study differed substantially from predictive models developed by AWG researchers, indicating that this study's use of qualitative textual analysis did not merely replicate expected outcomes.

Coding used nodes, which are references in data to concepts that may be either terminal variables or points of connection in networked concepts (Bazeley and Jackson 2013). Annotations and journal notes were made throughout the process, explaining the coding, analyzing relationships among nodes, and exploring the ideas behind the coded text (Bazeley and Jackson 2013, Bringer et al. 2014). The coding outcomes were subjected to critical analyses, questioning and revealing assumptions behind them and identifying gaps and weaknesses in the assessments. For each passage coded, Arnold carefully examined the text, its 
Fig. 1. Framework of drivers of systemic change.

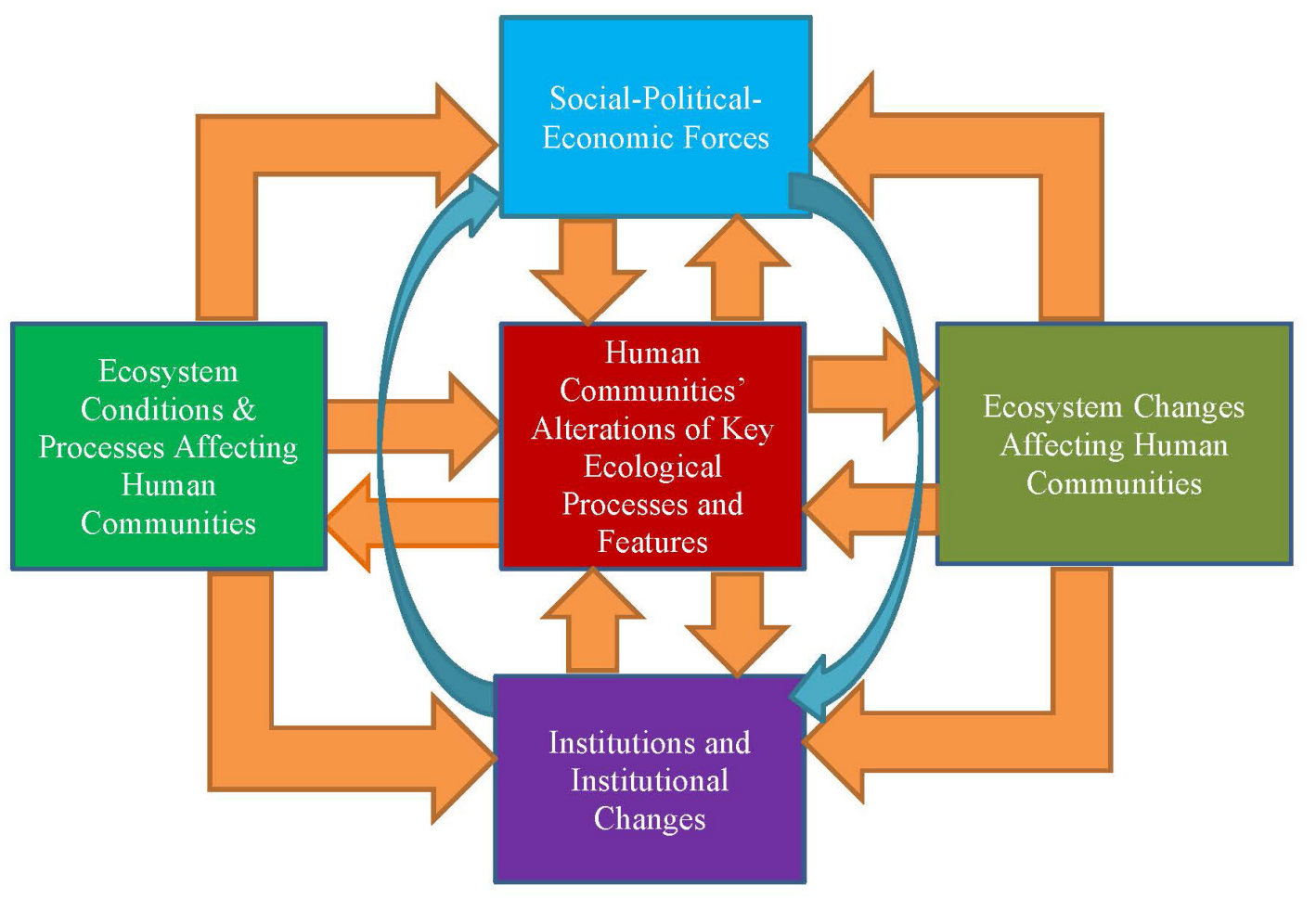

wording, and the conceptual and organizational relationship of the passage to the entire basin assessment. He also questioned the extent to which the coding of each passage reflected his biases and preconceptions, instead of the authors' intended meaning. He evaluated whether there were any logical inferences from the text and compared the coding of the passage to the coding of other passages in all the basin assessments. He compared the coding of the passage to other possible meanings and terminology. When an early iteration of coding was arguably less than faithful to the text and its meaning, he adjusted the coding accordingly. Self-reflection is a standard method of qualitycontrol for inductive textual analysis (Strauss 1987, Corbin and Strauss 1990, Bazeley and Jackson 2013, Bringer et al. 2014, Bettez 2015)

After all the coding was completed, we focused on nodes that appeared in at least 5 of the 6 assessments: a total of 100 nodes appearing in all 6 assessments and 23 nodes appearing in 5 of the 6 assessments. By using a five-out-of-six rule for including a node, we based our results on features appearing in several different types of basins assessments, yet avoided excluding a feature that may be present in every basin but overlooked by just one basin assessment team or may be implicit in that team's assessment but missed in the coding process. These 123 nodes were synthesized by exploring the relative importance of and relationships among each theme, concept, or variable to the assessments. The final iterations of analysis involved aggregation and synthesis of these nodes into two forms: a framework of broad categories and relationships and a list of relevant variables. This was done for both systemic-change drivers and adaptive-governance features. The broad frameworks are more interpretive than descriptive and the lists are more descriptive than interpretive, but both forms remain faithful to the assessment texts (Thomas and Harden 2008). Nonetheless, the insights we have gained from inductively coding and synthesizing the basin assessment texts are limited by the fact that the basin assessments themselves were logicaldeductive syntheses of existing literature and studies, shaped by the common research interests and guided cross-disciplinary dialogues of the AWG participants.

\section{RESULTS AND DISCUSSION}

Drivers of systemic change

The results of our textual analysis and synthesis of the crossassessment drivers of systemic change appear in two forms. Figure 1 depicts the major categories of change drivers and their relationships. Appendix 2 contains a lengthy, detailed list of specific change drivers within each category that were identified in at least five of the six basin assessments, similar to Ostrom's SES framework (Ostrom 2009, Table 1).

In Figure 1, the strong influence of ecosystem conditions, processes, and changes on entire-system change is represented on both the left and right sides of the diagram. All of the assessments described presettlement and postsettlement ecosystem conditions and processes (left side box) that strongly affected human efforts to inhabit, obtain food from, build economic activity within, relate 
to, and govern the basin. These ecosystem conditions and processes have affected how humans have altered the ecosystem, as well as the structure of society (social-political-economic forces) and institutions. As humans have altered ecosystems, the changes have had ecosystem-services feedbacks to society, affecting human communities (right side box), as well as ecosystems' structure and function (leftward feedback arrow to left side box). These feedbacks affect social-political-economic forces and governance institutions, as well the ways in which humans continue to alter ecosystems. For example, negative feedbacks to human communities have prompted efforts to restore watershed features and processes or manage the basin for ecological function, including changes in laws, governance goals, and public environmental values. The separate left-side and rightside boxes for ecosystems reflect the assessments' substantial and distinct attention to both ecosystems' structures/functions and ecosystems' services to society.

Central to systemic change in North American water basins is alteration of key ecological features and processes by human communities (middle box). Humans have changed ecosystem structures, functions, and processes through land-use activities, re-engineering of hydrological structure and processes, alteration of the land-water nexus, climate change, and conservation practices (Appendix 2).

Figure 1 analyzes the "social system" component of linked socialecological systems in three parts: human communities' alteration of key ecological features and processes (middle box), socialpolitical-economic forces (upper middle box), and institutions and institutional changes (lower middle box). Consistent with the ISED Framework (Arnold et al. 2014) and Sjöstedt (2015), all basin assessments gave special attention to institutions and their dynamics, which are certainly part of society and interconnected with societal forces yet also analytically different than societal forces.

We identified four major categories of change-driving forces with intertwined social, political, and economic dimensions (Appendix 2). The first category is economic valuation and exploitation of nature, especially societal and political treatment of environmental features and services as commodifiable resources for exploitation and consumption. The second category is societal growth and development, particularly settlement and migration trends, urbanization, population growth, land development, and technology. The third category is socio-political activity. This includes the exercise of and conflict over power, public values and norms, social inequity (especially the oppression and marginalization of indigenous peoples and racial and ethnic minorities), mobilization and activism, and socio-political change. The fourth category is social-interaction dynamics. Conflict and collaboration, trust and distrust in communities, and cultural and spiritual beliefs and practices are aspects of socialinteraction dynamics that received substantial cross-basin analysis.

Institutions and institutional change received substantial attention as a major change-driver category, as reflected in Figure 1. The effects of social-political-economic forces on the basins were strengthened through their institutionalization. For example, economic goals were incorporated into basingovernance policies to support agriculture and development, forces of oppression and marginalization were institutionalized in slavery, segregation, and Native-American conquest and displacement, and environmentalism became codified in environmental statutes and regulations. In addition, the structure of governance has influenced systemic change in the basins. Federal, state, local, and hybrid formal-informal governance entities, organized in fragmented, cross-scale governance systems, have influenced change, particularly by providing infrastructure, financial resources, and planning. The institutionalized missions of government agencies have changed over time, and adaptive methods and tools (e.g., adaptive management) have emerged.

All six basin assessments gave much attention to legal activity and legal institutions, including the roles of legislation, regulation, litigation, enforcement, and judicial decision making. Legal institutions have contributed to change by disturbing the status quo and granting legal authority to governance entities. They have resisted change through rigid rules and entrenchment of the status quo, eventually triggering systemic change when governance institutions proved too brittle and inflexible. Changes in legal institutions have contributed to broad systemic changes. For example, Congress adopted land-disposal and river-management laws in the nineteenth and early twentieth centuries that altered the Columbia, Klamath, and Platte basins, and new watershed governance institutions emerged in the Anacostia in the shadow of the Clean Water Act's evolving enforcement. Institutional change generally was a major theme in all basin assessments.

Our analysis of the basin assessments also reveals the significant cross-category effects that social-political-economic forces, human alterations of ecosystems, and institutions have had on one another, consistent with the predictions of the ISED Framework (Arnold et al. 2014). These effects are cumulative, synergistic, and iterative.

Cumulative effects result from the aggregation of multiple drivers. For example, in the Klamath basin, the combination of the basin's hydrological processes, emergent agricultural activities, economic forces, human settlement and population growth, legal regimes, governance institutions for irrigation-oriented basin management, and drought-condition feedbacks to local communities and economies produced a re-engineering and reallocation of the basin's hydrological system to support agriculture.

Synergistic effects result from the dynamic interaction of multiple drivers that produce effects greater or different than the mere sum of the parts. In the Anacostia, for example, urbanization, land development, population growth, pollution generation, stormwater runoff, river-flow conditions, deforestation, wetland loss, private property rights, and institutionalized economicdevelopment policies have intersected and reinforced one another to produce shallow, sluggish, sediment-filled, and polluted river conditions and the risk of hydrological collapse. Likewise, in the Middle Rio Grande basin, the intersecting effects of deforestation, fire suppression norms and practices, invasive bark-beetle infestation, drought, climate change, and land-use activity in the wildland-urban interface have changed forest and basin systems in ways that are more than merely cumulative, resulting in frequent, intense, and system-changing fires.

Iterative effects occur when one set of changes produces another set of changes that leads to yet another set of changes, and so 
forth. In the Platte River basin, economic-driven alterations of basin hydrology had imperiled species and produced negative ecosystem-services feedbacks by the early 1970s. Emergent environmentalist values, activism, and interest-group power led to congressional enactment of the Endangered Species Act, which in turn begat a series of disruptive regulatory and enforcement actions over time. A dam relicensing requirement brought together Nebraska, Colorado, and Wyoming to negotiate a restoration and adaptive-management agreement. A change in Nebraska law authorized integrated water management, in turn removing a major barrier to Nebraska's ability to enter into the tristate agreement. From the agreement have emerged adaptive management methods, ecological restoration projects, land and water conservation, and new plans and policies for the basin. Through multiple iterations, the Platte River basin's governance system has changed.

A very large number of relevant variables contribute to systemic change in water basins (Appendix 2), a result of our textual analyses that surprised us. We expected to find only a few major drivers of change, or perhaps several at most, that were common to all or nearly all basin assessments, consistent with panarchy models that posit only a few major variables drive systemic change across adaptive cycles (Holling et al. 2002, Walker et al. 2012, Walker and Salt 2012). Nonetheless the cross-assessment data show patterns of many drivers of change in the basins that were studied. If we were to narrow this list, we would have been unfaithful to the texts of the basin assessments themselves; we did not want to cherry-pick the drivers of change based on personal biases or untested theories.

There are four possible explanations for this numerosity. First, not all variables contribute to all changes. Each basin assessment analyzed several major systemic changes over time, ranging from 3 to 15 depending on how the team defined the system's core structure and the nature of change. Thus, some of the variables driving change toward environmental exploitation, basin reengineering, and minority-group oppression were different than some of the variables driving change toward environmentalism, ecosystem restoration, and inter-group cooperation.

Second, most assessments did not clearly categorize the types of change-contributing variables that they described. Some of what has been included in the list may have been triggers or disturbances, mere contributors to change, or subdrivers of change, instead of standing alone as major drivers per se. In addition, most assessments did not clearly classify drivers as slow variables or fast variables (Holling et al. 2002, Walker et al. 2012, Walker and Salt 2012), or differentiate between exogenous drivers and endogenous variables (Walker et al. 2012). The basin assessments consistently described many variables working together, i.e., cumulative, synergistically, and iteratively, to cause systemic change. Some variables that may have started out slowly at large geographic scales seem to have ended up operating quickly at small geographic scales (e.g., urbanization in the Anacostia or climate change in the Middle Rio Grande). If researchers were to attempt to narrow the major drivers of change over the postsettlement history of a complex social-ecologicalinstitutional basin system to a small number, they would either have created a list at the broad category level of generality reflected in Figure 1 or have a list that ignored relevant variables and therefore sacrificed truth.
Third, complex systems are exactly that: complex. Water basins are dynamic ecological-social-institutional systems with many features and processes that are interconnected through many linear and nonlinear cross-system feedbacks that are changing over time. Lengthy lists may be needed to describe the many interacting variables that have caused changes in these complex systems over the historical periods studied by the basin assessment teams. In attempting to describe how complex socialenvironmental systems (SES) work and how institutions for SES governance emerge, Elinor Ostrom developed similarly long lists of relevant variables for analysis: 6 categories and 47 variables in her social-ecological systems (SES) framework, and 8 design principles, 21 categories, and over 300 terms and concepts in her institutional analysis and development (IAD) framework (Ostrom 2009, McGinnis 2011). According to Sjöstedt (2015), institutions in complex SES should be studied for both exogenous and endogenous drivers of change that do not have simple ecosystem or social-system proxies.

Fourth, our study's lengthy list of change drivers is a starting point for further research on the variables affecting water basins and other SES. The list of relevant variables can and should be refined through further empirical studies of systemic changes, including both qualitative case studies and the development and testing of quantitative models using statistical-analysis tools.

\section{Features of adaptive governance}

Our analysis and synthesis of the six basin assessments also produced a relatively lengthy list of features of adaptive governance, provided in full in Appendix 3 and summarized in Table 3. These features were identified in all or all-but-one of the assessments as characteristics that made the basin governance systems adaptive or would be needed to make the basin governance systems adaptive. They fall into four major categories: the goals, structure, methods, and resources of the governance system. The categories were derived from inductive synthesis of the coded nodes from the basin assessment texts.

Table 3. Framework of features of adaptive governance.

\begin{tabular}{|c|c|c|c|}
\hline Goals & Structure & Methods & Resources \\
\hline \multirow[t]{5}{*}{$\begin{array}{l}\text { Poly-resilience } \\
\text { social goals }\end{array}$} & Polycentric & Flexibility & $\begin{array}{l}\text { Socio-political } \\
\text { capacity }\end{array}$ \\
\hline & Networked & Learning & $\begin{array}{l}\text { Government } \\
\text { resources }\end{array}$ \\
\hline & Scaled & $\begin{array}{l}\text { Resource } \\
\text { management for } \\
\text { ecosystem } \\
\text { functions and } \\
\text { processes }\end{array}$ & $\begin{array}{l}\text { Use of law and } \\
\text { institutions for } \\
\text { adaptation and } \\
\text { transformation }\end{array}$ \\
\hline & Modular & $\begin{array}{l}\text { Integrated } \\
\text { problem solving }\end{array}$ & \\
\hline & $\begin{array}{l}\text { Participatory } \\
\text { Legitimate }\end{array}$ & Accountability & \\
\hline
\end{tabular}

The governance system's goals affect its adaptive character. According to the basin assessments, adaptive governance aims to enhance the resilience of desired ecosystems, social systems, and institutional systems, not just the resilience of one system or subset of systems. This is known as poly-resilience (Arnold and Gunderson 2013). In contrast, water governance in each basin 
has, at times, maladaptively made the basin more vulnerable to undesirable transformation by favoring the resilience of some systems, such as exploitative economies or property-rights institutions, over the resilience of other systems, such as naturalflow watersheds or marginalized human communities. Given the strong influence of public values and norms on governance decisions, social norms must evolve so that the public value polyresilience as a societal goal if governance is to become adaptive. Resource problems must be reframed so that multiple goals match the multidimensional nature of the problems. Poly-resilience also requires that resources be managed for ecosystem functions and processes in integrated ways.

The basin assessments identified several features of governance structure that facilitate adaptive governance. Adaptive governance is polycentric and modular, yet connected through multistakeholder and multigovernment networks. Adaptive governance has nested scales of governance that are matched to the problem scale, the government system's capacity, ecological scale (i.e., the basin), and the smallest appropriate level for the function (i.e., subsidiarity). The public and multiple stakeholders participate meaningfully in water governance and accept the legitimacy of the governance system, because they have robust opportunities for participation and deliberation.

In adaptive governance, officials and stakeholders use a variety of methods for adaptively managing complex social-ecologicalinstitutional systems, such as multiscenario planning, ecological restoration, green infrastructure, land-use management, adaptive ecosystem management, and many others. The overarching themes of adaptive governance methods are flexibility, learning, resource management for ecosystem functions and processes, integrated problem solving, and accountability. In particular, flexibility is embedded in governance, and adaptive capacity is developed. Both expert/scientific and public/social learning occur through experimentation, monitoring, feedback loops, and adaptive management. Ecosystem functions and processes are served by both conservation of key ecosystem features and governance or management actions that deliberately transform the ecosystem toward a desirable state. These ecosystem functions and processes must be assessed regularly for resilience in the context of the basin's interlinked systems. Integrated problem solving is also a method used in adaptive governance. Furthermore, accountability is a critical feature, achieved through the use of identified performance measures, regulations and laws, and cross-system feedbacks, which signal which governance decisions or societal behaviors undermine the resilience and functioning of the basin.

Finally, resources are essential to adaptive governance. One set of resources centers on socio-political capacity, including social capital (especially cooperation and trust), communication, social and institutional innovation, and the power to decide and act. A second set of resources is about social change, including social mobilization, political action, evolving public values, and government facilitation of social change. Law and institutions form a third set of resources for adaptive governance. Law serves as a disturbance that stimulates adaptation and/or transformation, provides the authority to act, and is a tool to achieve accountability or transformation. Legal flexibility, reform, and change are common features of adaptive governance systems. Institutional changes trigger other institutional changes and build adaptive capacity in basin systems.

This synthesis framework of cross-assessment adaptivegovernance features overlaps considerably with, yet differs somewhat from, other conceptualizations of adaptive governance generally (e.g., Walker and Salt 2012, Chaffin et al. 2014a) and in the AWG project (e.g., Cosens et al. 2014a, DeCaro et al. 2017). Differences between this framework and other frameworks appear in both their conceptual structures and their specific features. The advantages of this study's synthesis framework are: (1) it is based on broadly cross-interdisciplinary patterns that pervade assessments of water governance in six diverse basins; and (2) it is built from coding, analysis, and synthesis of the language and ideas of the assessment texts themselves through an iterative inductive process, instead of speculative theory or cherry-picked features that support prior assumptions about the nature of adaptive governance.

\section{IMPLICATIONS FOR RESILIENCE AND ADAPTIVE- GOVERNANCE RESEARCH}

Our study has resulted in cross-interdisciplinary knowledge about systemic-change drivers and adaptive-governance features from syntheses of patterns in the texts of six diverse interdisciplinary assessments of basin resilience. Four key insights form this study should inform research on resilience and adaptive governance in complex social-ecological-institutional systems.

First, the alteration of key ecological features and processes by human communities is the central driver of system change, affecting the structures and functions of ecosystems, social systems, and institutions. The adaptive governance of water basins must pay particular attention to land-use activities (including both land development and agricultural activities), the alteration of hydrologic structures and processes, the alteration of the land-water nexus, climate change, and emergent conservation and restoration practices. This is consistent with much of the social-ecological resilience literature (e.g., Gunderson and Holling 2002, Light et al. 2005, Olsson et al 2006). It cautions against too much emphasis on abstract principles of adaptive governance that are disconnected from the core problem of human alteration of key ecological features and processes in ecological-social-institutional systems, an inquiry that has tempted the attention of AWG scholars (e.g., Arnold and Gunderson 2013, Chaffin et al. 2014b). Furthermore, our study shows that the central focus on human change to ecosystems has increasingly come to include restoration of ecological functions and features in water basins and management for natural processes (e.g., flows, biotic infrastructure, forest and/or fire regimes).

Second, more research should explore the many different drivers of change in complex social-ecological-institutional systems, instead of seeking to identify a few major drivers of change as is often urged in the literature (Holling et al. 2002, Walker et al. 2012, Walker and Salt 2012). The "few drivers" imperative may be more theoretically driven than empirically supported, as suggested by the very large number of variables in Appendix 2, which were identified as drivers of change in at least five of the six basin assessments. For example, where the broad category of societal growth and development drove systemic change, it often involved settlement and migration, urbanization, population 
growth, land use and development, and technology. Likewise, ecosystem feedbacks to human communities that drove changes in policies and actions included drought, flooding, fire, species decline or loss, wetland loss, altered hydrology, and climate change, among others. Legal-system processes are many and diverse (e.g., litigation, legislation, regulation, enforcement) and can serve as change-causing disturbances, facilitators of transformation, or resistance to change. At the very least, the Ostrom-style table of relevant variables in Appendix 2 should serve as a reference for the study of system-change drivers in water basins and encourage others to gather thorough cross-basin lists of relevant variables before determining which are the most significant.

Third, the six basin assessments showed that institutions matter and that the term "social-ecological-institutional systems" is often more appropriate than merely social-ecological systems. Institutions are systems that are distinct from the social, political, and economic forces and systems that affect and are affected by social systems and ecosystems. This meta-analysis study supports the increasingly intentional analysis of institutions in complexsystem dynamics and adaptive governance (e.g., Cosens 2014a, Garmestani and Allen 2014, Sjöstedt 2015). However, it also encourages researchers to study institutions, social systems, and ecosystems as cross-dynamic, each continuously changing and affecting each other across time. Even though resilience theory is based on nonlinear cross-system dynamics (Gunderson and Holling 2002), many social-ecological-institutional systems tend to be described in linear cause-and-effect ways, such as when economic and political interests demand flood control and stable water supplies, which leads to institutionalization of major dam building on rivers, which in turn causes a decline in natural flow regimes and aquatic biodiversity (e.g., Birge et al. 2014). This historical narrative is practically unavoidable, yet fails to represent accurately the ongoing instabilities and evolutions of each (sub) system throughout the basin's transformation. The Framework of Drivers of Systemic Change in Figure 1, as well as the ISED Framework in Arnold et al. (2014), help to focus systemic analysis on the continuous evolutions and transformations in systems and the effects of these changes on other systems. Moreover, the emergence of the institutional and social system characteristics to support adaptive governance can serve as drivers of change, and drivers of change can form the features of adaptive governance (Olsson et al. 2006). For example, in the six basin assessments, policy innovation, socio-cognitive reframing processes, multistakeholder networks, and improved social capital, among others, were both drivers of change and features of adaptive governance.

Fourth, despite the concern of much of the adaptive-governance literature with facilitating adaptive management of complex systems (Chaffin et al. 2014f $a$ ), this meta-analysis of six waterbasin resilience assessments suggests that more attention should be given to the role of adaptive governance in facilitating social change and changes in social values. More change in the six basins occurred when public values and socio-political forces changed than when administrative methods or scientific approaches to basin management changed. For example, public attitudes and social forces for both the consumptive exploitation of natural systems and the marginalization and oppression of minority groups strongly shaped the transformation of the river basins' environmental conditions, societal functions, and governance institutions. Environmentalism, the activism of historically marginalized groups, socio-cognitive reframing processes, and shifts from conflict to collaboration and distrust to trust have stimulated efforts at ecosystem restoration in many basins, as well as moves toward adaptive governance systems with sufficient socio-political capacity to support social, ecological, and institutional transformations.

Nonetheless, the relevance of this meta-analysis on resilience and adaptive-governance research is somewhat constrained by inherent limits in the underlying assessments, and these limits suggest the need for further research. Most significantly, the basin assessments were qualitative case studies, using historical narrative and both qualitative and quantitative data combined without a single standardized model or methodology. Future research should focus on whether the frameworks and features identified in this study are replicated in other resilience assessments of complex social-ecological-institutional systems. Formal modeling and quantitative analyses of systemic-change drivers and adaptive-governance features should also be pursued in the future, yet further qualitative analyses are also important to understand these complex and context-dependent phenomena.

The basin assessments were limited to North America, with five of the six basins entirely in the United States. Future research should evaluate the extent to which the AWG project's frameworks and insights about complex SES governance apply to basins and other SES outside of North America, in which political, economic, socio-cultural, and legal systems will differ from the United States.

The remaining suggestions for further research involve concepts or variables that were identified strongly in some but fewer than five of the basin assessments. For example, three types of ecosystem changes were strongly present in some but not all basin assessments: forest management and deforestation, soil changes, and invasive or nonnative species. We do not know whether these variables are not universal in basin systemic changes or whether they were present in all basins but just omitted from some assessments. Future research should pay attention to these potential change drivers.

The assessments' attention to socioeconomic class dynamics as a driver of change was tied narrowly to the oppression and marginalization of indigenous peoples and people of color. As a whole, the assessments did not consistently consider wealth/ income inequality or economic-class dynamics independently as significant drivers of change. We urge more attention to this variable. We also encourage attention to the intersection of educational levels, economic and social dislocation, and political activism, which may combine to create major disruptions to adaptive governance and therefore to basin resilience.

Public education is often touted by scholars, managers, policy makers, and stakeholders as important to effectuate governance change and improve adaptive capacity in watersheds (Olsson et al 2006, Birkmann et al. 2010). However, only four of the basin assessments identified public education as a driver of change. This variable needs further attention in future research, including rigorous study of its efficacy in achieving change. 
Given the assessments' documentation of the strong effects of social inequity, oppression, and marginalization on basin conditions and governance, we were surprised to see that only about one-half of the assessments identified social justice, equitable conditions, social-justice activism, or community-based activism as important features of adaptive governance systems. It may be that some basin assessment teams implicitly treated social justice and activism as a part of legitimacy, participation, or social change. However, the Everglades assessment characterized Native American tribes' assertion of their rights through litigation as a maladaptive feature of the current system. Moreover, the lack of explicit attention to social justice and activism as a part of adaptive governance systems is troubling in the light of critics' charges that resilience scholarship fails to address structural inequities in society and the power arrangements behind social-ecological-institutional systems (Cote and Nightingale 2012, MacKinnon and Derickson 2013). Resilience analysis can be used to expose structural inequities in the social benefits and vulnerabilities of ecosystems and the roles of social, political, and economic forces that oppress marginalized groups (Langridge et al. 2006, Ernstson 2013, Walsh-Dilley, et al. 2013, Arnold et al. 2014). We call for more systematic and explicit attention to social justice, equitable conditions, social-justice activism, and community-based activism as features of adaptive governance systems.

Three assessments identified institutional stability as a feature of adaptive governance, whereas all six assessments identified institutional change as a feature. Despite the seeming contradiction between the two features, governance systems need a balance of stability and change if they are to function effectively (Craig et al. 2017). A governance system that is undergoing many constant changes across all dimensions of the system will produce negative feedbacks to human communities, society, and ecosystems and will lack adaptive capacity; some degree of stability is required if adaptive planning and management are to be implemented. More study should be made of the types, roles, and scope of institutional stability in adaptive governance.

\section{CONCLUSION}

This qualitative meta-analysis of diverse interdisciplinary studies for common patterns, concepts, and variables produce crossinterdisciplinary insights that are useful to understanding complex phenomena, unhindered by the constraints of individual disciplines or narrow approaches to cross-disciplinary research. The frameworks and lists of variables for systemic-change drivers and adaptive-governance features that emerged from our qualitative textual analyses of six North American basin assessments form potentially generalizable knowledge about adaptive governance and resilience in complex social-ecologicalinstitutional systems. They suggest that research on resilience and adaptive governance should: (1) focus on the alteration of key ecological features and processes by human communities as the central driver of system change; (2) explore the many different drivers of change in complex social-ecological-institutional systems, instead of seeking to identify a few major drivers of change; (3) treat complex systems as social-ecologicalinstitutional systems and intentionally analyze institutions as different than social-political-economic forces; and (4) emphasize the role of adaptive governance in facilitating social change and changes in social values, not just facilitating adaptive management of resources and the environment. Based on our study, we make three recommendations: (1) the governance of complex social-ecological-institutional systems should be studied through interdisciplinary collaborative projects similar to the AWG project; (2) qualitative textual meta-analyses of diverse interdisciplinary studies should be used to generate crossinterdisciplinary knowledge; and (3) the frameworks and lists generated by this study should be applied and refined in future studies of complex social-ecological-institutional systems to improve our knowledge of adaptive governance and resilience across disciplines.

Responses to this article can be read online at: http://www.ecologyandsociety.org/issues/responses. $\mathrm{php} / 9734$

\section{Acknowledgments:}

This research is part of a synthesis project on Social-ecological System Resilience, Climate Change, \& Adaptive Water Governance, cochairs B. Cosens and L. Gunderson, with the National SocioEnvironmental Synthesis Center (SESYNC) under funding from the National Science Foundation DBI-1052875. This research was also funded by the University of Louisville Boehl Chair Endowment Fund.

\section{LITERATURE CITED}

Arnold, C. A. 2004. Working out an environmental ethic: anniversary lessons from Mono Lake. Wyoming Law Review 4:1-55. [online] URL: https://papers.ssrn.com/sol3/papers.cfm? abstract_id $=1025857$

Arnold, C. A., O. O. Green, D. DeCaro, A. Chase, and J.-G. Ewa. 2014. The social-ecological resilience of an eastern urbansuburban watershed: the Anacostia River Basin. Idaho Law Review 51(1):29-90. http://dx.doi.org/10.2139/ssrn.2584968

Arnold, C. A., and L. H. Gunderson. 2013. Adaptive law and resilience. Environmental Law Reporter 43:10426-10443. [online] URL: https://ssrn.com/abstract=2225619

Bazeley, P., and K. Jackson. 2013. Qualitative data analysis with NVivo. Second edition. Sage, Thousand Oaks, California, USA.

Benson, M. H., D. Llewellyn, R. Morrison, and M. Stone. 2014. Water governance challenges in New Mexico's Middle Rio Grande Valley: a resilience assessment. Idaho Law Review 51 (1):195-228. http://dx.doi.org/10.2139/ssrn.2464387

Bettez, S. C. 2015. Navigating the complexity of qualitative research in postmodern contexts: assemblage, critical reflexivity, and communion as guides. International Journal of Qualitative Studies in Education 28(8):932-954. http://dx. doi. org/10.1080/09518398.2014.948096

Birge, H. E., C. R. Allen, R. K. Craig, A. S. Garmestani, J. A. Hamm, C. Babbitt, K. Nemec, and E. Schlager. 2014. Socialecological resilience and law in the Platte River Basin. Idaho Law Review 51(1):229-256.

Birkmann, J., M. Garschagen, F. Kraas, and N. Quang. 2010. Adaptive urban governance: new challenges for the second 
generation of urban adaptation strategies to climate change. Sustainability Science 5(2):185-206. http://dx.doi.org/10.1007/ $\underline{\text { s11625-010-0111-3 }}$

Bringer, J. D., L. H. Johnston, and C. H. Brackenridge. 2004. Maximizing transparency in a doctoral thesis: the complexities of writing about the use of QSR NVIVO within a grounded theory study. Qualitative Research 4(2):247-265. http://dx.doi. org/10.1177/1468794104044434

Chaffin, B. C., R. K. Craig, and H. Gosnell. 2014b. Resilience, adaptation, and transformation in the Klamath River Basin social-ecological system. Idaho Law Review 51(1):157-193. [online] URL: https://ssrn.com/abstract=2449381

Chaffin, B. C., H. Gosnell, and B. A. Cosens. 2014a. A decade of adaptive governance scholarship: synthesis and future directions. Ecology and Society 19(3):56. http://dx.doi.org/10.5751/ ES-06824-190356

Corbin, J. M., and A. Strauss. 1990. Grounded theory research: procedures, canons, and evaluative criteria. Qualitative Sociology 13:3-21. http://dx.doi.org/10.1007/BF00988593

Cosens, B. A., and A. K. Fremier. 2014. Assessing system resilience and ecosystem services in large river basins: a case study of the Columbia River Basin. Idaho Law Review 51(1):91-125. [online] URL: https://ssrn.com/abstract=2717747

Cosens, B. A., L. H. Gunderson, C. R. Allen, and M. H. Benson. 2014b. Identifying legal, ecological and governance obstacles, and opportunities for adapting to climate change. Sustainability 6:2338-2356. http://dx.doi.org/10.3390/su6042338

Cosens, B. A., L. H. Gunderson, and B. C. Chaffin. 2014a. The adaptive water governance project: assessing law, resilience and governance in regional socio-ecological water systems facing climate change. Idaho Law Review 51(1):1-27. [online] URL: https://ssrn.com/abstract $=2519236$

Cote, M., and A. J. Nightingale. 2012. Resilience thinking meets social theory: situating social change in socio-ecological systems (SES) research. Progress in Human Geography 36(4):475-489. http://dx.doi.org/10.1177/0309132511425708

Craig, R. K., A. S. Garmestani, C. R. Allen, C. A. Arnold, H. Birgé, D. A. DeCaro, A. K. Fremier, H. Gosnell, and E. Schlager. 2017. Balancing stability and flexibility in adaptive governance: an analysis of tools available in U.S. environmental law. Ecology and Society 22(2):3. http://dx.doi.org/10.5751/ES-08983-220203

DeCaro, D. A., B. C. Chaffin, E. Schlager, A. S. Garmestani, and J. B. Ruhl. 2017. Legal and institutional foundations of adaptive environmental governance. Ecology and Society 22(1):32. http:// dx.doi.org/10.5751/ES-09036-220132

DeCaro, D. A., and M. K. Stokes. 2013. Public participation and institutional fit: a social-psychological perspective. Ecology and Society 18(4):40. http://dx.doi.org/10.5751/ES-05837-180440

DeWulf, A., G. François, C. Pahl-Wostl, and T. Tailieu. 2007. A framing approach to cross-disciplinary research collaboration: experiences from a large-scale research project on adaptive water management. Ecology and Society 12(2):14. http://dx.doi. org/10.5751/ES-02142-120214
Eisenhardt, K. M., and M. E. Graebner. 2007. Theory building from cases: opportunities and challenges. Academy of Management Journal 50(1):25-32. http://dx.doi.org/10.5465/ AMJ.2007.24160888

Ernstson, H. 2013. The social production of ecosystem services: a framework for studying environmental justice and ecological complexity in urbanized landscapes, 109 Landscape and Urban Planning 109:7-17. http://dx.doi.org/10.1016/j.landurbplan.2012.10.005

Fairclough, N. 2005. Critical discourse analysis in transdisciplinary research. Pages 53-70 in R. Wodak and P. Chilton, editors. New agenda in (critical) discourse analysis: theory, methodology and interdisciplinarity. John Benjamins, Philadelphia, Pensylvania, USA. http://dx.doi.org/10.1075/dapsac.13.06fai

Fry, G. L. A. 2001. Multifunctional landscapes-towards transdisciplinary research. Landscape and Urban Planning 57:159-168. http://dx.doi.org/10.1016/S0169-2046(01)00201-8

Garmestani, A. S., and C. R. Allen, editors. 2014. Socialecological resilience and law. Columbia University Press, New York, New York, USA. http://dx.doi.org/10.7312/garm16058

Gray, B. 2008. Enhancing transdisciplinary research through collaborative leadership. American Journal of Preventive Medicine. 35(2):S124-S132. http://dx.doi.org/10.1016/j. amepre.2008.03.037

Grubert, E., and A. Siders. 2016. Benefits and applications of interdisciplinary digital tools for environmental meta-reviews and analyses. Environmental Research Letters 11(9):093001. http://dx. doi.org/10.1088/1748-9326/11/9/093001

Gunderson, L. H., B. A. Cosens, B. C. Chaffin, C. A. (T.) Arnold, A. K. Fremier, A. S. Garmestani, R. K. Craig, H. Gosnell, H. E. Birge, C. R. Allen, M. H. Benson, R. R. Morrison, M. C. Stone, J. A. Hamm, K. Nemec, E. Schlager, and D. Llewellyn. 2017. Regime shifts and panarchies in regional scale social-ecological water systems. Ecology and Society 22(1):31. http://dx.doi. org/10.5751/ES-08879-220131

Gunderson, L. H., A. Garmestani, K. W. Rizzardi, J. B. Ruhl, and A. Light. 2014. Escaping a rigidity trap: governance and adaptive capacity to climate change in the Everglades social ecological system. Idaho Law Review 51(1):127-156.

Gunderson, L. H., and C. S. Holling, editors. 2002. Panarchy, understanding transformations in human and natural systems. Island, Washington, D.C., USA.

Heemskerk, M., K. Wilson, and M. Pavao-Zuckerman. 2003. Conceptual models as tools for communication across disciplines. Conservation Ecology 7(3):8. http://dx.doi.org/10.5751/ES-00554-070308

Holling, C. S., L. H. Gunderson, and G. D. Peterson. 2002. Sustainability and panarchies. Pages 63-102 in L. H. Gunderson and C.S. Holling, editors. Panarchy, understanding transformations in human and natural systems. Island, Washington, D.C., USA.

Langridge, R., J. Christian-Smith, and K. A. Lohse. 2006. Access and resilience: analyzing the construction of social resilience to the threat of water security. Ecology and Society 11(2):18. http:// dx.doi.org/10.5751/ES-01825-110218 
Light, S. S., L. H. Gunderson, and C. S. Holling. 2005. The Everglades: evolution of management in a turbulent system. Pages 103-168 in L. H. Gunderson, C. S. Holling, and S. S. Light, editors. Barriers and bridges to the renewal of ecosystems and institutions. Columbia University Press, New York, New York, USA.

MacKinnon, D., and K. D. Derickson. 2013. From resilience to resourcefulness: a critique of resilience policy and activism. Progress in Human Geography 37:253-270. http://dx.doi. org/10.1177/0309132512454775

McGinnis, M. D. 2011. An introduction to IAD and the language of the Ostrom workshop: a simple guide to a complex framework for the analysis of institutions and their development. Policy Studies Journal 39:169-183. http://dx.doi.org/10.1111/

j.1541-0072.2010.00401.x

Noblit, G. W., and R. D. Hare. 1988. Meta-ethnography: synthesizing qualitative studies. Sage, Thousand Oaks, California, USA. http://dx.doi.org/10.4135/9781412985000

Olsson, P., C. Folke, and T. Hahn. 2004. Social-ecological transformation for ecosystem management: the development of adaptive co-management of a wetland landscape in southern Sweden. Ecology and Society 9(4):2. http://dx.doi.org/10.5751/ ES-00683-090402

Olsson, P., L. H. Gunderson, S. R. Carpenter, P. Ryan, L. Lebel, C. Folke, and C. S. Holling. 2006. Shooting the rapids: navigating transitions to adaptive governance of social-ecological systems. Ecology and Society 11(1):18. http://dx.doi.org/10.5751/ ES-01595-110118

O'Rourke, M., and S. J. Crowley. 2013. Philosophical intervention and cross-disciplinary science: the story of the Toolbox Project. Synthese 190(11):1937-1954. http://dx.doi.org/10.1007/s11229-012-0175$\mathrm{y}$

Ostrom, E. 2009. A general framework for analyzing sustainability of social-ecological systems. Science 325:419-422. $\underline{\text { http://dx.doi.org/10.1126/science.1172133 }}$

Resilience Alliance. 2007. Assessing resilience in social-ecological systems: a workbook for scientists. Version 1.1. Resilience Alliance.

Resilience Alliance. 2010. Assessing resilience in social-ecological systems: workbook for practitioners. Version 2.0. Resilience Alliance. [online] URL: https://www.resalliance.org/resilienceassessment

Scheffer, M., F. Westley, W. A. Brock, and M. Holmgren. 2002. Dynamic interaction of societies and ecosystems - linking theories from ecology, economy, and sociology. Pages 195-239 in L. H. Gunderson and C.S. Holling, editors. Panarchy, understanding transformations in human and natural systems. Island, Washington, D.C., USA.

Shaffer, D. W., D. Hatfield, G. N. Svarovsky, P. Nash, A. Nulty, E. Bagley, K. Frank, A. A. Rupp., and R. Mislevy. 2009. Epistemic network analysis: a prototype for $21^{\text {st }}$ century learning. International Journal of Learning and Media 1(2):1-21. [online] URL: http://citeseerx.ist.psu.edu/viewdoc/download?

$\underline{\text { doi }=10 \cdot 1 \cdot 1 \cdot 188.470 \& r e p=\text { rep } 1 \& \text { type }=p d f}$
Sjöstedt, M. 2015. Resilience revisited: taking institutional theory seriously. Ecology and Society 20(4):23. http://dx.doi.org/10.5751/ ES-08034-200423

Stokols, D., R. Harvey, J. Gress, J. Fuqua, and K. Phillips. 2005. In vivo studies of transdisciplinary scientific collaboration. American Journal of Preventive Medicine 28(2S2):202-213. http:// dx.doi.org/10.1016/j.amepre.2004.10.016

Strauss, A. L. 1987. Qualitative analysis for social scientists. Cambridge University Press, Cambridge, UK. http://dx.doi. org/10.1017/CBO9780511557842

Thomas, J., and A. Harden. 2008. Methods for the thematic synthesis of qualitative research in systematic reviews. $B M C$ Medical Research Methodology 8:45. http://dx.doi. org/10.1186/1471-2288-8-45

Walker, B. H., S. R. Carpenter, J. Rockström, A.-S. Crépin, and G. D. Peterson. 2012. Drivers, "slow" variables, "fast" variables, shocks, and resilience. Ecology and Society 17(3):30. http://dx.doi. org/10.5751/ES-05063-170330

Walker, B., and D. Salt. 2012. Resilience practice: building capacity to absorb disturbance and maintain function. Island, Washington, D.C., USA. http://dx.doi.org/10.5822/978-1-61091-231-0

Walsh-Dilley, M., W. Wolford, and J. McCarthy. 2013. Rights for resilience: bringing power, rights and agency into the resilience framework. Oxfam America, Washington, D.C., USA. [online] URL: http://www.atkinson.cornell.edu/Assets/ACSF/docs/collaborations/ oxfam/R4R $\% 20$ Conceptual $\% 20$ Framework.pdf 
Appendix 1. Basin assessment authors' disciplines

Self-reported disciplines of basin assessment authors with AWG core team members highlighted.

Basin

Anacostia

Anacostia

Anacostia

Anacostia

Anacostia

Columbia

Columbia

Everglades

Everglades

Everglades

Everglades

Everglades

Klamath

Klamath

Klamath

Middle Rio Grande

Middle Rio Grande

Middle Rio Grande

Middle Rio Grande

Platte

Platte

Platte

Platte

Platte

Platte

Platte

Platte
Author

Tony Arnold

Olivia Odom Green

Daniel DeCaro

Alexandra Chase

Jennifer-Grace Ewa

Barb Cosens

Alex Fremier

Lance Gunderson

Ahjond Garmestani

Keith Rizzardi

J.B. Ruhl

Fred Light

Brian Chaffin

Robin Craig

Hannah Gosnell

Melinda Benson

Dagmar Llewellyn

Ryan Morrison

Mark Stone

Hannah Birge

Craig Allen

Robin Craig

Ahjond Garmestani

Joseph Hamm

Christina Babbitt

Kristine Nemec

Edella Schlager
Disciplines

Law; Planning; Political Science; History; Public

Policy

Law; Hydrology; Geology; Public Policy

Psychology; Political Science; Economics

Law; Public Policy; Anthropology; Sociology

Planning; Law; Geography; Public Policy

Law; Geology; Geochemistry

Ecology; Geography; Environmental Science;

Mathematics

Environmental Engineering; Environmental

Science; Ecology; Natural Resource Management

Law; Public Policy; Wildlife Ecology

Law; Public Administration

Economics; Law; Geography

Law; Political Science

Geography; Environmental Science

English Literature and Literary Theory; Science

Writing; Law

Geography; American Civilization

Law; Geography; Environmental Studies; Natural

Resource Management

Hydrology

Civil Engineering; Water Resource Management;

Ecology

Civil Engineering; Hydrology

Ecology; Soil Biochemistry; Natural Resource

Management

Wildlife Ecology; Biology; Ecology;

Environmental Science

English Literature and Literary Theory; Science

Writing; Law

Law; Public Policy; Wildlife Ecology

Law; Psychology; Natural Resource Management

Natural Resource Management; Environmental

Science; International Relations; Public Policy

Natural Resource Management; Biology

Political Science; Public Policy; Anthropology;

Economics 


\section{Appendix 2 .}

Drivers of systemic change in North American water basins

1. Ecosystem Conditions and Processes Affecting Human Communities

1.1. Hydrological Conditions and Processes

1.1.a. General hydrological conditions and processes

1.1.b. Drought (e.g., $\rightarrow$ water storage, irrigation)

1.1.c. Flooding (e.g., $\rightarrow$ flood control projects)

1.1.d. Groundwater levels and dynamics (e.g., $\rightarrow$ dependence $\&$ uncertainty)

1.2. Geological or Topographical Conditions and Changes (e.g., $\rightarrow$ settlement patterns)

1.3. Fire (e.g., $\rightarrow$ fire suppression)

1.4. Extreme or Traumatic Events; Disasters

1.5. Ecosystem Services and Feedbacks (e.g., $\rightarrow$ exploitation)

2. Human Communities' Alterations of Key Ecological Features and Processes

2.1. Land Use Activities

2.1.a. Agricultural activities

2.1.b. Land use and development

2.2. Alteration of Hydrologic Structure and Processes

2.2.a. Engineered infrastructure and systems

2.2.b. Altered stream and riparian structure(s)

2.2.c. Altered stream flows

2.2.d. Water demand and supply-demand mismatches

2.3. Alteration of Land-Water Nexus

2.3.a. Pollution

2.3.b. Runoff

2.3.c. Wetland alteration or loss

2.4. Climate Change

2.5. Conservation Practices

2.5.a. Use or conservation of green infrastructure

2.5.b. Land conservation practices

2.5.c. Ecological restoration

3. Social-Political-Economic Forces

3.1. Economic Valuation and Exploitation of Nature

3.1.a.. Treatment of environmental features and services as commodifiable resources for exploitation and consumption

3.1.b. Forces of economic development and production

3.1.c. Cross-scale economic forces

3.1.d. Public values and norms

3.1.d.i. Change in public values and norms over time

3.1.d.ii. Psychology of human connection to place and framing/reframing of watersheds

3.1.e. Technology and engineered infrastructure as tools for exploiting nature 
3.1.f. Business organization behavior

3.2. Societal Growth and Development

3.2.a. Settlement, resettlement, and migration

3.2.b. Urbanization

3.3.c. Population growth

3.3.d. Land use and development

3.4.e. Technology

3.3. Socio-Political Activity

3.3.a. Power

3.3.a.i. Interest group power and conflict

3.3.b. Public values and norms

3.3.b.i. Economic (consumption, commodification, exploitation)

3.3.b.ii. Public health considerations

3.3.b.iii. Environmentalism

3.3.b.iv.. Framing \& reframing (psychology)

3.3.b.v. Change in public values and norms over time

3.3.c. Social inequity

3.3.c.i.. Oppression and marginalization

3.3.c.ii. Indigenous peoples

3.3.c.iii. Racial and ethnic minorities; structural racism

3.3.c.iv. Socio-economic class

3.3.d. Mobilization and activism

3.3.d.i. Community-based mobilization and activism.

3.3.d.ii. Political mobilization and activism.

3.3.d.iii. Environmentalism.

3.3.e. Socio-political change

3.4. Social-Interaction Dynamics

3.4.a. Conflict and collaboration

3.4.b. Trust and distrust

3.4.c. Culture and spirituality

4. Institutions and Institutional Changes

4.1. Institutionalization of Social-Political-Economic Forces

E.g., Economic goals and values

E.g., Oppression and marginalization (indigenous communities, racial and ethnic minorities)

E.g., Environmentalism

4.2. Governance Structure

4.2.a. Cross-Scale governance

4.2.b. Fragmentation of governance

4.2.c. Mixed and hybrid governance institutions (e.g., formal-informal)

4.2.d. Federal resource ownership and management

4.2.e. State and local governments (polycentric structure)

4.2.f. Government-created infrastructure 
4.2.g. Government-provided financial resources

4.2.h. Planning

4.2.i. Changes in governance agency mission

4.2.j. Emergence of adaptive methods and tools (e.g., adaptive management)

4.3. Legal Activity and Legal Institutions

4.3.a. Legislation

4.3.b. Regulation

4.3.c. Enforcement

4.3.d. Litigation

4.3.e. Judicial decisions

4.3.f. Law as disturbance (e.g., altering status quo)

4.3.g. Law as facilitator (e.g., grant of authority)

4.3.h. Law as resistance and entrenchment (e.g., rigid rules)

4.3.i. Changes in legal institutions

4.4. Institutional Change

4.4.a. Emergence: graduate \& organic development of new regimes

4.4.b. Evolution: incremental modifications to existing regimes

4.4.c. Hybridization: new regimes from synthesis of 2+ existing regimes

4.4.d. Transformation: complete shift from 1 regime to another regime

4.4.e. Revolution: sudden, radical change in regimes

5. Ecosystem Changes Affecting Human Communities: Ecosystem Services Feedbacks

5.1. Extreme or Traumatic Events or Disturbances

5.1.a. Drought

5.1.b. Flooding

5.1.c. Fire

5.2. Decline or Loss of Ecosystem Features on which Humans Depend

5.2.a. Species decline or loss

5.2.b. Alteration or loss of wetlands

5.2.c. Alteration of stream flows and water flows

5.3. Major Systemic Changes

5.3.a. Altered hydrology

5.3.b. Climate change

5.3.c. Green infrastructure performance 


\section{Appendix 3.}

Features of adaptive governance in North American water basins

1. Goals

1.1. Poly-Resilience Social Goals (resilience of multiple interconnected systems)

1.1.a. Resilience of ecosystems, social systems, and institutions

1.1.b. Public values and goals embrace and emphasize poly-resilience

1.1.c. Changing public values and norms

1.1.d. Resource management for ecosystem functions and processes

1.1.e. Reframing problems and resource governance

1.1.f. Integrated problem solving

2. Structure

2.1. Polycentric Governance Structure

2.2. Networked Structure

2.2.a. Multi-stakeholder and multi-government networks

2.3. Modular Governance or Social Organization

2.4. Scaled Governance

2.4.a. Governance scaled to problem and capacity

2.4.b. Ecological scale $=$ watershed or basin scale

2.4.c. Nested scales

2.4.d. Subsidiarity: scaling to smallest appropriate level

2.5. Public and Multi-Stakeholder Participation

2.6. Perceived Legitimacy (Public Acceptance) of Governance

3. Methods

3.1. Flexibility

3.1.a. Development of adaptive capacity

3.1.b. Embedded flexibility

3.1.c. Experimentation

3.1.d. Innovation

3.1.e. Multiple strategies

3.1.f. Multi-scenario planning

3.1.g. Reframing problems and resource governance

3.1.h. Adaptive management

3.2. Learning

3.2.a. Assessment of systems for resilience

3.2.b. Experimentation

3.2.c. Monitoring

3.2.d. Feedback loops

3.2.e. Expert/scientific learning

3.2.f. Public/social learning

3.2.g. Adaptive management

3.3. Resource Management for Ecosystem Functions and Processes

3.3.a. Assessment of systems for resilience 
3.3.b. Conservation of key ecosystem features

3.3.c. Deliberate ecosystem transformation

3.3.d. Ecological restoration

3.3.e. Green infrastructure

3.3.f. Land use management

3.4. Integrated Problem Solving

3.5. Accountability

3.5.a. Implementation and performance measures

3.5.b. Regulation

3.5.c. Law as a tool of accountability

3.5.d. Tight or strong cross-system feedbacks [but not too tight]

4. Resources

4.1. Socio-Political Capacity

4.1.a. Collaboration, cooperation, trust, and social capital generally

4.1.b. Communication

4.1.c. Innovation (especially social and institutional innovation)

4.1.d. Power

4.2. Social Change

4.2.a. Social mobilization and political action

4.2.b. Public values and norms

4.2.c. Government resources

4.3. Use of Law and Institutions for Adaptation and Transformation

4.3.a. Institutional Change

4.3.a.i. As a trigger of other institutional changes

4.3.a.ii. As adaptive capacity

4.3.b. Law

4.3.b.i. As a disturbance that stimulates adaptation and/or transformation

4.3.b.ii. As authority to act

4.3.b.iii. As a tool of accountability and transformation

4.3.b.iv. Legal flexibility

4.3.b.v. Legal reform and legal change 